\title{
Toxin profile of Alexandrium catenella from the Chilean coast as determined by liquid chromatography with fluorescence detection and liquid chromatography coupled with tandem mass spectrometry
}

\author{
Bernd Krock $^{\mathrm{a}, *}$, Carmen Gloria Seguel ${ }^{\mathrm{b}}$, Allan D. Cembella ${ }^{\mathrm{a}}$ \\ ${ }^{a}$ Alfred-Wegener Institut für Polar- und Meeresforschung, Am Handelshafen 12, 27570 Bremerhaven, Germany \\ ${ }^{\mathrm{b}}$ Universidad de Tarapacá, Avda. General Velásquez 1775, Arica, Chile
}

Received 18 October 2006; received in revised form 10 February 2007; accepted 25 February 2007

\begin{abstract}
The profile of tetrahydropurine neurotoxins associated with paralytic shellfish poisoning (PSP) was determined from a Chilean strain of the marine dinoflagellate Alexandrium catenella. The toxin composition was compared with that of toxic shellfish, presumably contaminated by natural blooms of $A$. catenella from the same region in southern Chile. Ion pair-liquid chromatography with post-column derivatization and fluorescence detection (LC-FD) was employed for relative quantitative analysis of the toxin components, whereas unambiguous identification of the toxins was confirmed by tandem mass spectrometry (LC-MS/MS). In the dinoflagellate strain from Chile, the $N$-sulfocarbamoyl derivatives (C1/C2, B1) and the carbamoyl gonyautoxins GTX1/GTX4 comprise $>90 \%$ of the total PSP toxin content on a molar basis. This toxin composition is consistent with that determined for $A$. catenella populations from the Pacific coast in the northern hemisphere. The characteristic toxin profile is also reflected in the shellfish, but with evidence of epimerization and metabolic transformations of C1 and C2 to GTX2 and GTX3, respectively. This work represents the first unequivocal identification and confirmation of such PSP toxin components from the Chilean coast.

(C) 2007 Elsevier B.V. All rights reserved.
\end{abstract}

Keywords: Alexandrium catenella; LC-FD; LC-MS/MS; PSP toxins; Toxic dinoflagellates

\section{Introduction}

The tetrahydropurine toxins associated with paralytic shellfish poisoning (PSP) are potent neurotoxins active on voltage-gated sodium channels of excitable cells (Kao and Walker, 1982). These toxins can be divided into three structural groups (Fig. 1) based on the nature of the side chain: carbamoyl $\left(\mathrm{R} 4=-\mathrm{CONH}_{2}\right), N$-sulfocarbamoyl $\left(\mathrm{R} 4=-\mathrm{CONHSO}_{3}{ }^{-}\right)$and decarbamoyl $(\mathrm{R} 4=-\mathrm{H})$. This family of PSP toxins includes saxitoxin and more than 20

\footnotetext{
* Corresponding author. Tel.: +49 4831 2055; fax: +49 48312115

E-mail address: Bernd.Krock@awi.de (B. Krock).
}

naturally occurring related compounds (Onodera et al., 1997; Kodama, 2000). These toxins are produced by marine dinoflagellates belonging to the genera Alexandrium, Pyrodinium and Gymnodinium, as well as by certain species of freshwater and brackish water cyanobacteria (Hall et al., 1990; Carmichael, 1994). Suspension-feeding shellfish can be vectors of such phytoplanktonic toxins via accumulation in their tissues, but these toxins can also move directly through pelagic food chains, affecting zooplankton, fish, birds and marine mammals (Mortensen, 1985).

In Chile the presence of PSP is endemic in the southern part of the ocean littoral. In these Austral 


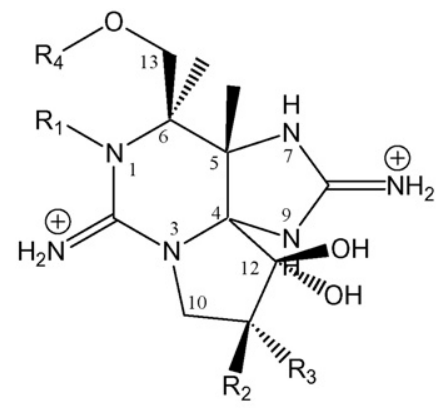

\begin{tabular}{|l|l|l|c|c|c|}
\hline & & & Carbamoyl & N-Sulfocarbamoyl & Decarbamoyl \\
\hline $\mathrm{R} 1$ & $\mathrm{R} 2$ & $\mathrm{R} 3$ & $\mathrm{R} 4:$ & $\mathrm{R} 4:$ & $\mathrm{R} 4:$ \\
$\mathrm{CONH}_{2}$ & $\mathrm{CONHSO}_{3}^{-}$ & $\mathrm{H}$ \\
\hline $\mathrm{H}$ & $\mathrm{H}$ & $\mathrm{H}$ & $\mathrm{STX}$ & $\mathrm{B} 1$ & $\mathrm{dcSTX}$ \\
\hline $\mathrm{OH}$ & $\mathrm{H}$ & $\mathrm{H}$ & $\mathrm{NEO}$ & $\mathrm{B} 2$ & dcNEO \\
\hline $\mathrm{OH}$ & $\mathrm{H}$ & $\mathrm{OSO}_{3}^{-}$ & $\mathrm{GTX} 1$ & $\mathrm{C} 3$ & dcGTX1 \\
\hline $\mathrm{H}$ & $\mathrm{H}$ & $\mathrm{OSO}_{3}^{-}$ & $\mathrm{GTX} 2$ & $\mathrm{C} 1$ & dcGTX2 \\
\hline $\mathrm{H}$ & $\mathrm{OSO}_{3}^{-}$ & $\mathrm{H}$ & $\mathrm{GTX} 3$ & $\mathrm{C} 2$ & dcGTX3 \\
\hline $\mathrm{OH}$ & $\mathrm{OSO}_{3}^{-}$ & $\mathrm{H}$ & $\mathrm{GTX} 4$ & $\mathrm{C} 4$ & dcGTX4 \\
\hline
\end{tabular}

Fig. 1. Naturally occurring PSP toxins found among various marine dinoflagellates and toxin vector organisms, including carbamate, $N$ sulfocarbamoyl, and decarbamoyl derivatives. Saxitoxin = STX; neosaxitoxin = NEO; gonyautoxins 1,2,3,4=GTX 1,2,3,4; B1 (=GTX5); B2 (=GTX6); dc = decarbamoyl toxins.

Regions, Alexandrium catenella has been reported as the main agent responsible for PSP toxin occurrence and shellfish contamination (Muñoz, 1985; Cassis et al., 2002; Lagos, 2003). A. catenella was first recorded in the Magellan strait in 1972 and since then its known range in Chilean waters has expanded from $55^{\circ} 55^{\prime} \mathrm{S}$ to $44^{\circ} 44^{\prime} \mathrm{S}$. Furthermore, the seasonal frequency and dispersion also appears to be increasing (Guzmán et al., 2002). During the last three decades, several hundred people in Chile have suffered from PSP syndromes, and more than 25 humans have died after shellfish consumption. As a consequence, quarantines have frequently been imposed on shellfish collection, transportation and commercialization. Since 1991, PSP outbreaks have been recorded continuously in this geographical area. Most studies on PSP toxin occurrence and composition in Chile have been devoted to the analysis of these toxins in shellfish, such as the Chilean blue mussel Mytilus chilensis (Andrinolo et al., 2002;
García et al., 2004), the striped mytilid (or Chilean ribbed mussel) Aulacomya ater (native name "cholga") (García et al., 2005), and two carnivorous gastropods, Concholepas (native name "loco") and Argobuccinum ranelliformes (native name "caracol del sur") (Compagnon et al., 1998). Some research has also been conducted on toxin kinetics and dynamics of PSP toxin components of A. catenella in mammalian subjects (Andrinolo et al., 2002). Nevertheless, the toxin profile of the causative organisms in Chile has not been heretofore clearly identified and confirmed by advanced analytical methods.

This article reports the first confirmatory analysis of a Chilean strain of A. catenella simultaneously carried out by liquid chromatography with post-column derivatization followed by fluorescence detection (LC-FD) and with tandem mass spectrometry (LCMS/MS). These data are compared with PSP toxin profiles reported from mussels of the same temporal and 
geographical provenance, with respect to the processes of biotransformation and toxin metabolism in associated toxic shellfish.

\section{Materials and methods}

\subsection{Culture and harvest of A. catenella}

A Chilean strain ACC02 of the dinoflagellate $A$. catenella was isolated from live phytoplankton samples collected in the Coastal Channel, XI Region of Chile in 1994. Cultured cells were kindly provided by Dr. Sandra Madariaga and Ms. Miriam Seguel, Universidad Austral de Chile, Puerto Montt. Cells were grown in L1enriched seawater growth medium (Guillard, 1972) at $16{ }^{\circ} \mathrm{C}$ on a $16: 8 \mathrm{~h}$ light:dark photocycle and harvested in late exponential phase.

The cell pellets were harvested by centrifugation $\left(3220 \times g, 15 \mathrm{~min}\right.$ at $\left.4{ }^{\circ} \mathrm{C}\right)$, suspended in $1.0 \mathrm{ml}$ of $0.03 \mathrm{M}$ acetic acid, and subsequently transferred into a FastPrep tube containing $0.9 \mathrm{~g}$ of lysing matrix D. The samples were homogenized by reciprocal shaking at maximum speed (6.5) for $45 \mathrm{~s}$ in a Bio101 FastPrep instrument (Thermo Savant, Illkirch, France). After homogenization, samples were centrifuged (Eppendorf $5415 \mathrm{R}$, Hamburg, Germany) at $16,100 \times g$ at $4{ }^{\circ} \mathrm{C}$ for $15 \mathrm{~min}$. The supernatant $(400 \mu \mathrm{l})$ was transferred to a spin-filter (pore-size $0.45 \mu \mathrm{m}$, Millipore Ultrafree, Eschborn, Germany) and centrifuged for $30 \mathrm{~s}$ at $800 \times g$. The filtrate was analyzed by LC-FD with post-column derivatization and LC-MS/MS, respectively.

\subsection{Analytical reagents}

Water was deionized and purified (Milli-Q, Millipore $\mathrm{GmbH}$, Eschborn, Germany) to $18 \mathrm{M} \Omega \mathrm{cm}^{-1}$ quality or better. Formic acid (90\%, p.a.), acetic acid (p.a.) and ammonium formate (p.a.) were purchased from Merck (Darmstadt, Germany), nitric acid (p.a.) and phosphoric acid (p.a.) were from AppliChem (Darmstadt, Germany, periodic acid, 1-heptanesulphonic acid, 1-octanesulphonic acid and diammonium hydrogenphosphate were from Sigma (Deisenhofen, Germany). The solvents, methanol, tetrahydrofurane (THF) and acetonitrile, were high performance liquid chromatography (HPLC) grade (Merck, Darmstadt, Germany).

Standard solutions of PSP toxins (saxitoxin, STX, neosaxitoxin, NEO, decarbamoyl saxitoxin, dcSTX, gonyautoxins $1 \& 4$, GTX1/GTX4, gonyautoxins $2 \& 3$, GTX2/GTX3, decarbamoyl gonyautoxins 2\&3, dcGTX2/dcGTX3, and B1) were purchased from the
Certified Reference Material Programme of the Institute for Marine Biosciences, National Research Council, Halifax, NS, Canada.

\subsection{Analytical methods}

\subsubsection{Liquid chromatography with fluorescence detection $(L C-F D)$}

The LC-FD analysis was carried out on a LC1100 series liquid chromatograph (Agilent Technologies, Waldbronn, Germany) coupled to a PCX 2500 postcolumn derivatization system (Pickering Laboratories, Mountain View, CA, USA). The LC-system consisted of a G1379A degasser, a G1311A quaternary pump, a G1229A autosampler, a G1330B autosampler thermostat, a G1316A column thermostat and a G1321A fluorescence detector

Chromatographic conditions were as follows: mobile phase A: $6 \mathrm{mM}$ 1-octanesulphonic acid and $6 \mathrm{mM} \mathrm{1-}$ heptanesulphonic acid in $40 \mathrm{mM}$ ammonium phosphate, adjusted to $\mathrm{pH} 7.0$ with dilute phosphoric acid and $0.75 \%$ THF for the gonyautoxin group; mobile phase B: $13 \mathrm{mM}$ 1-octanesulphonic acid in $50 \mathrm{mM}$ phosphoric acid adjusted to $\mathrm{pH} 6.9$ with ammonium hydroxide and $15 \%(\mathrm{v} / \mathrm{v})$ of acetonitrile and $1.5 \%$ of THF for the saxitoxin group. The flow rate was $1 \mathrm{ml} \mathrm{min}{ }^{-1}$ with the following gradient: $0 \mathrm{~min}, 100 \% \mathrm{~A}$ isocratic to $15 \mathrm{~min}$, switch to $100 \% \mathrm{~B}$ until $16 \mathrm{~min}$, isocratic B until $35 \mathrm{~min}$, switch to $100 \%$ A until $36 \mathrm{~min}$, isocratic $100 \%$ A until $45 \mathrm{~min}$ (=total run time). The autosampler was cooled to $4{ }^{\circ} \mathrm{C}$ and the injection volume was $20 \mu \mathrm{L}$. The separation of analytes was performed on a $250 \mathrm{~mm} \times 4.6 \mathrm{~mm}$ i.d., $5 \mu \mathrm{m}$, Luna C18 reversed-phase column (Phenomenex, Aschaffenburg, Germany) equipped with a Phenomenex SecuriGuard pre-column. The eluate from the column was continuously oxidized with $10 \mathrm{mM}$ of periodic acid in $550 \mathrm{mM}$ ammonium hydroxide at a flow rate of $0.4 \mathrm{ml} \mathrm{min}{ }^{-1}$ in a reaction coil set at $50{ }^{\circ} \mathrm{C}$. Subsequently, the eluate was continuously acidified with $0.75 \mathrm{~N}$ nitric acid at a flow rate of $0.4 \mathrm{ml} \mathrm{min}^{-1}$ and the toxins were detected by a dual monochromator fluorescence detector $\left(\lambda_{\text {ex }} 333 \mathrm{~nm}\right.$; $\left.\lambda_{\text {em }} 395 \mathrm{~nm}\right)$. Data acquisition and processing was performed with the HP ChemStation software. The C-toxins were identified indirectly by desulfonation to the respective gonyautoxins with $1 \mathrm{M}$ hydrochloric acid at $90{ }^{\circ} \mathrm{C}$. Hydrolyzed samples were re-injected and gonyautoxin concentrations of the non-hydrolyzed samples were subtracted from the respective hydrolyzed samples. The obtained gonyautoxin concentration is equivalent to content of the respective $\mathrm{C}$-toxin (for chemical structures see 
Fig. 1). PSP toxin concentrations were determined by external calibration.

\subsubsection{Liquid chromatography coupled with tandem mass spectrometry ( $L C-M S / M S)$}

Mass spectral experiments were performed on an ABI-SCIEX-4000 Q Trap, triple quadrupole mass spectrometer equipped with a TurboSpray ${ }^{\circledR}$ interface coupled to an Agilent model 1100 LC. The LC equipment included a solvent reservoir, in-line degasser (G1379A), binary pump (G1311A), refrigerated autosampler (G1329A/G1330B), and temperature-controlled column oven (G1316A).

Mass spectrometric analyses for PSP toxins were performed according to the hydrophilic interaction liquid ion-chromatography (HILIC) method (Dell'Aversano et al., 2005) with slight modifications. The analytical column $(250 \mathrm{~mm} \times 2 \mathrm{~mm})$ was packed with $5 \mu \mathrm{m}$ TSK-gel Amide- $80^{\circledR}$ (Tosoh Bioscience LLC, Montgomeryville, PA, USA) and maintained at $35^{\circ} \mathrm{C}$. The flow rate was $0.2 \mathrm{ml} \mathrm{min}^{-1}$ and isocratic elution was performed with two eluants at a ratio of $35 \% \mathrm{~A}$ and $65 \% \mathrm{~B}$, where eluant $\mathrm{A}$ was water and $\mathrm{B}$ was acetonitrile/water $(95: 5, \mathrm{v} / \mathrm{v})$, both containing $2.0 \mathrm{mM}$ ammonium formate and $3.6 \mathrm{mM}$ formic acid ( $\mathrm{pH} 3.5$ ).

Multiple reaction monitoring (MRM) experiments were carried out in positive ion mode by selecting the following transitions (precursor ion $>$ fragment ion), period 1 (B-, C- and gonyautoxins): $\mathrm{m} / \mathrm{z}, 412>332$ and $\mathrm{m} / \mathrm{z} 412>314$ (for GTX1/GTX4 and C3/C4), $\mathrm{m} / \mathrm{z}$ $396>316$ and $m / z 396>298$ (for GTX2/GTX3, C1/C2 and B2), $m / z, 380>300$ and $m / z 380>282$ (for B1), $m / z$ $353>273$ (for dcGTX2/dcGTX3), $m / z 369>289$ (for dcGTX1/dcGTX4); period 2 (STX, NEO and their decarbamoyl derivatives): $\mathrm{m} / \mathrm{z}, 300>282$ and $\mathrm{m} / \mathrm{z} 300>$ 204 (for STX), $m / z \quad 316>298$ and $m / z 316>196$ (for NEO), $m / z 257>196$ and $m / z 257>156$ (for dcSTX) and $\mathrm{m} / z, 273>255$ (for dcNEO). Dwell times of 100$200 \mathrm{~ms}$ were used for each transition. For these studies the following source parameters were used: curtain gas: $30 \mathrm{psi}$, temperature: $650{ }^{\circ} \mathrm{C}$, ion-spray voltage: $5000 \mathrm{~V}$, gas 1 and 2: $70 \mathrm{psi}$, interface heater: on, collision gas: high, declustering potential: $50 \mathrm{~V}$, entrance potential $10 \mathrm{~V}$, collision energy: $30 \mathrm{~V}$ and collision cell exit potential: $16 \mathrm{~V}$.

\section{Results and discussion}

The PSP toxin profile of the cultured Chilean strain of A. catenella, as determined by LC-FD (Fig. 2), revealed the presence of the following toxins in decreasing order of molar percentage of total content: C1/C2 (57\%),
GTX1/GTX4 (24\%), B1 (=GTX5) (13\%), GTX2/GTX3 $(3 \%)$, NEO (2\%) and B2 (=GTX6) (1\%). The epimeric pairs (e.g. GTX1/GTX4) were separated analytically but shown here as combined because of facile epimerization to thermodynamic equilibrium during sample handing, preparation and storage. Saxitoxin, dcSTX, dcGTX2, dcGTX3, C3 and C4 were only present in trace amounts $(<1 \mathrm{~mol} \%)$.

Ion-pair chromatography with post-column derivatization and fluorescence detection is a common method for the determination of the highly hydrophilic PSP toxins. The PSP toxins, as non-fluorescent tetrahydro purine compounds, are first separated on a chromatographic column and after elution they are oxidized to fluorescent imino purine derivatives. Identification of toxins is achieved by comparison of retention time and fluorescence response at specified wavelengths to certified reference compounds. Nevertheless, although this method is very sensitive and can provide excellent quantitative results for known analogues and despite of is relatively high specificity, the technique is prone to artefacts and phantom peaks that compromise specificity (Jaime et al., 2001; Biré et al., 2003). For example, unknown compounds of bacterial origin may co-elute with and thus interfere with detection of GTX4 (Baker et al., 2003). Additionally, other fluorescent (but presumably nontoxic) cell constituents may elute very early in the chromatogram, thereby interfering with early eluting PSP toxins, especially with the $N$-sulfocarbamoyl Ctoxins and gonyautoxins.

We therefore assured unambiguous identification and confirmation of the toxin components by minor modifications of the HILIC-LC/MS method (Dell'Aversano et al., 2005), which does not involve ion-pair reagents and is thus compatible with mass spectrometry. The HILIC-LC/MS method confirmed the identity of the key toxins C1, C2, GTX1 and GTX4 in the Chilean strain of A. catenella, and also detected traces of toxins $\mathrm{C} 3$ and $\mathrm{C} 4$, which were not detectable with the LC-FD method. This is presumably due to different toxin response factors and detection limits of the respective methods (see Table 1). For example, the detection limit for GTX3 is lower by the fluorescence method than by mass spectrometry, but this pattern is reversed for the N1-hydroxy carbamoyl toxins such as GTX1/GTX4. Similarly, the $N$-sulfocarbamoyl epimeric pairs $\mathrm{C} 1 / \mathrm{C} 2$ are detectable by fluorescence at a lower concentration limit than the corresponding N1-hydroxy toxins C3/C4, even though the exact response factors could not be determined for the latter pair, because of the lack of certified standards. 

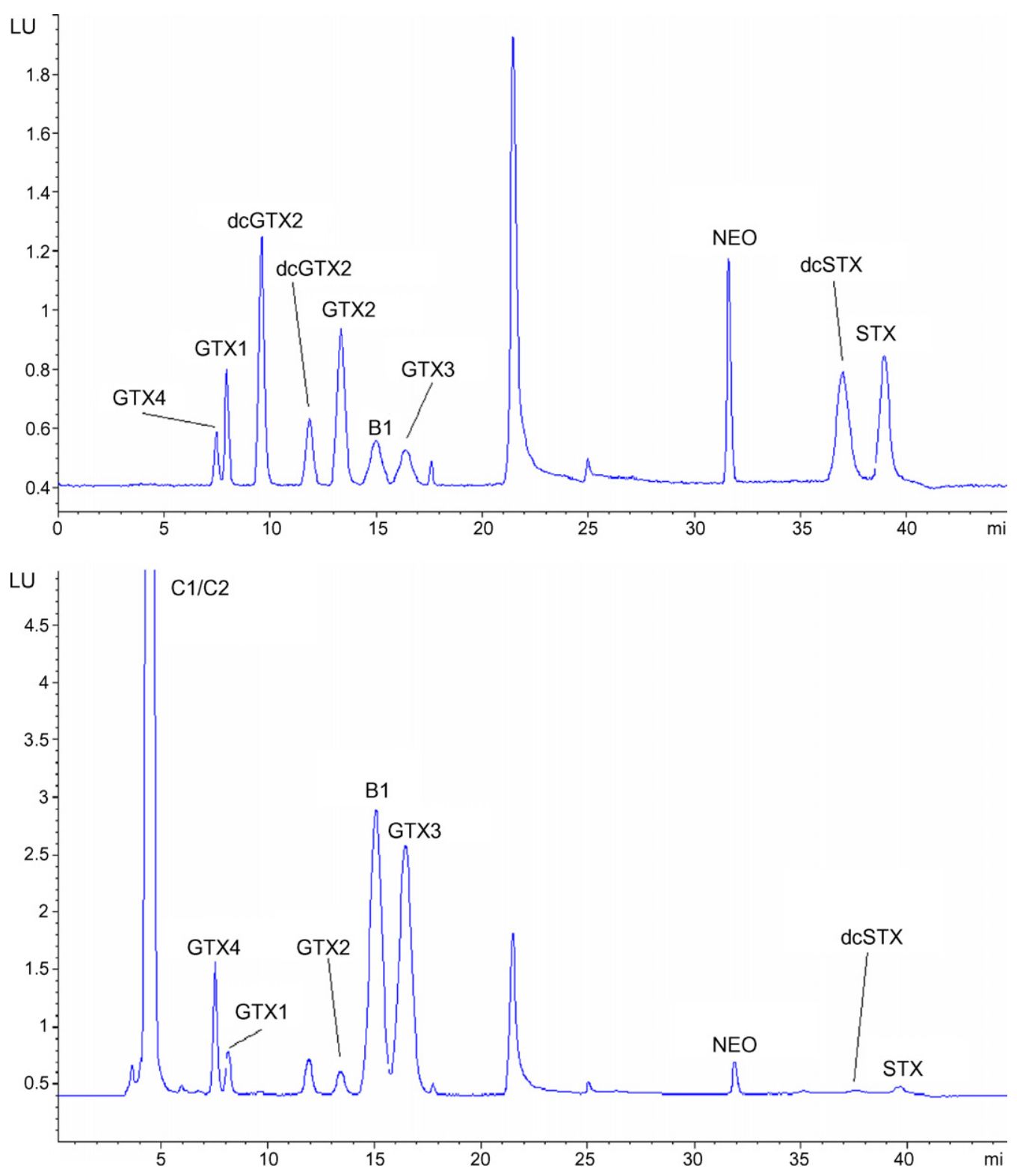

Fig. 2. LC-FD chromatograms of a PSP standard solution (top) and extract of cultured strain ACC02 of Alexandrium catenella from Chile (bottom).

Table 1

Relative response factors $(\mathrm{STX}=1.00)$ for PSP toxins detected by LC-FD and LC-MS/MS

\begin{tabular}{lll}
\hline Toxin & Response factor (fluorescence) & Response factor (tandem mass spectrometry) \\
\hline GTX4 & 0.03 & 0.15 \\
GTX1 & 0.02 & 0.01 \\
dcGTX2 & 0.87 & 0.01 \\
dcGTX3 & 1.07 & 0.03 \\
GTX2 & 0.91 & 0.01 \\
GTX5 & 0.17 & 0.12 \\
GTX3 & 1.19 & 0.22 \\
NEO & 0.08 & 0.05 \\
dcSTX & 1.08 & 0.41 \\
STX & 1.00 & 1.00 \\
\hline
\end{tabular}


For the first time, an analysis of the PSP toxin profile of A. catenella has been performed by liquid chromatography with post-column derivatization and fluorescence detection, and then compared with the profile determined by an LC-MS/MS technique with a high degree of sensitivity and specificity. The spectra of
A. catenella toxins (Fig. 3) are consistent with published LC-MS/MS spectra of PSP toxins (Dell'Aversano et al., 2005). A drawback of the HILIC-MS/MS method is the concentration- and matrix-dependence of the ionization of PSP toxins. For comparison, in Fig. 4 the total ion chromatogram of a reference sample is superimposed
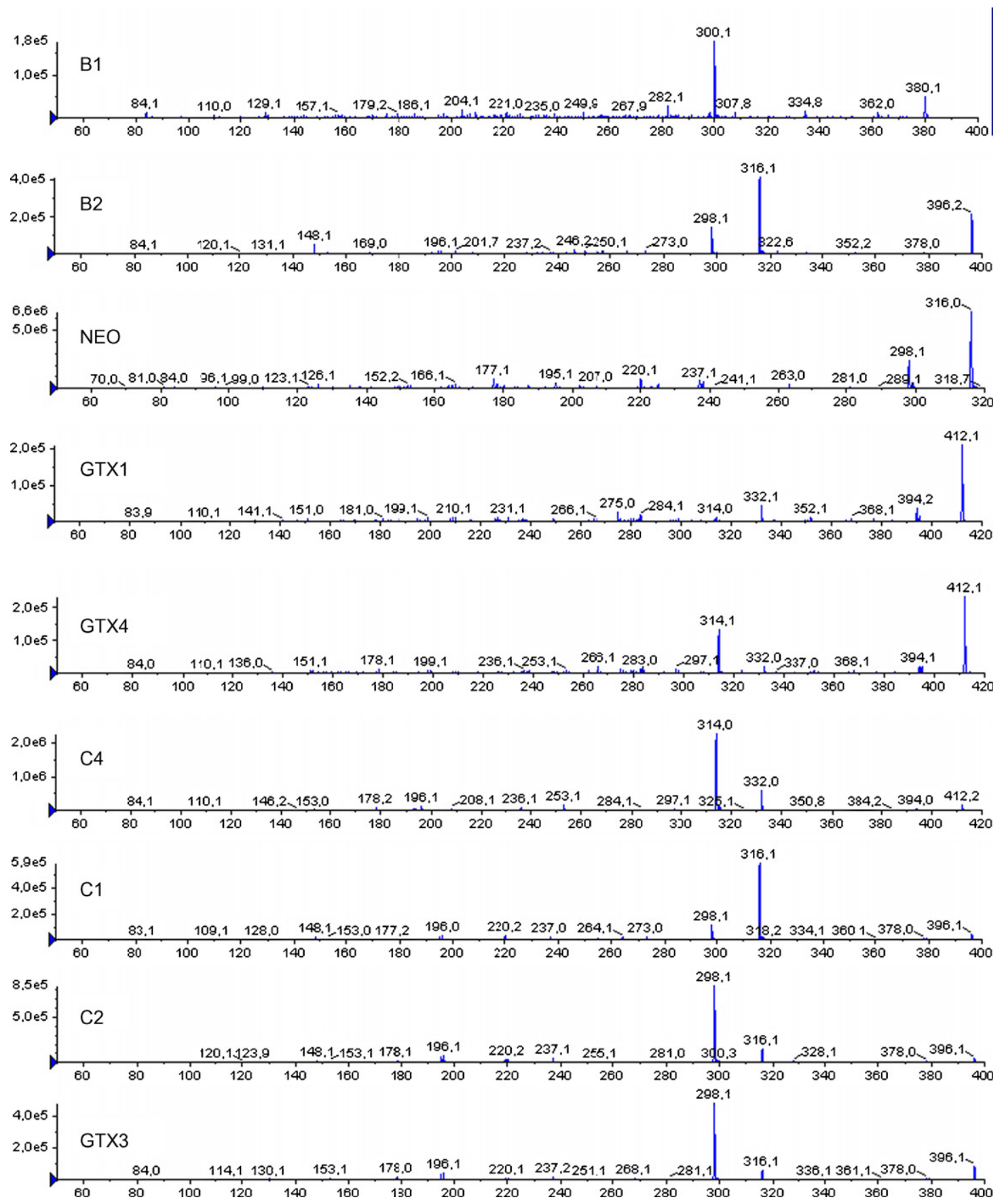

Fig. 3. MS/MS spectra of the most abundant PSP toxins in Chilean strain ACC02 of A. catenella. 

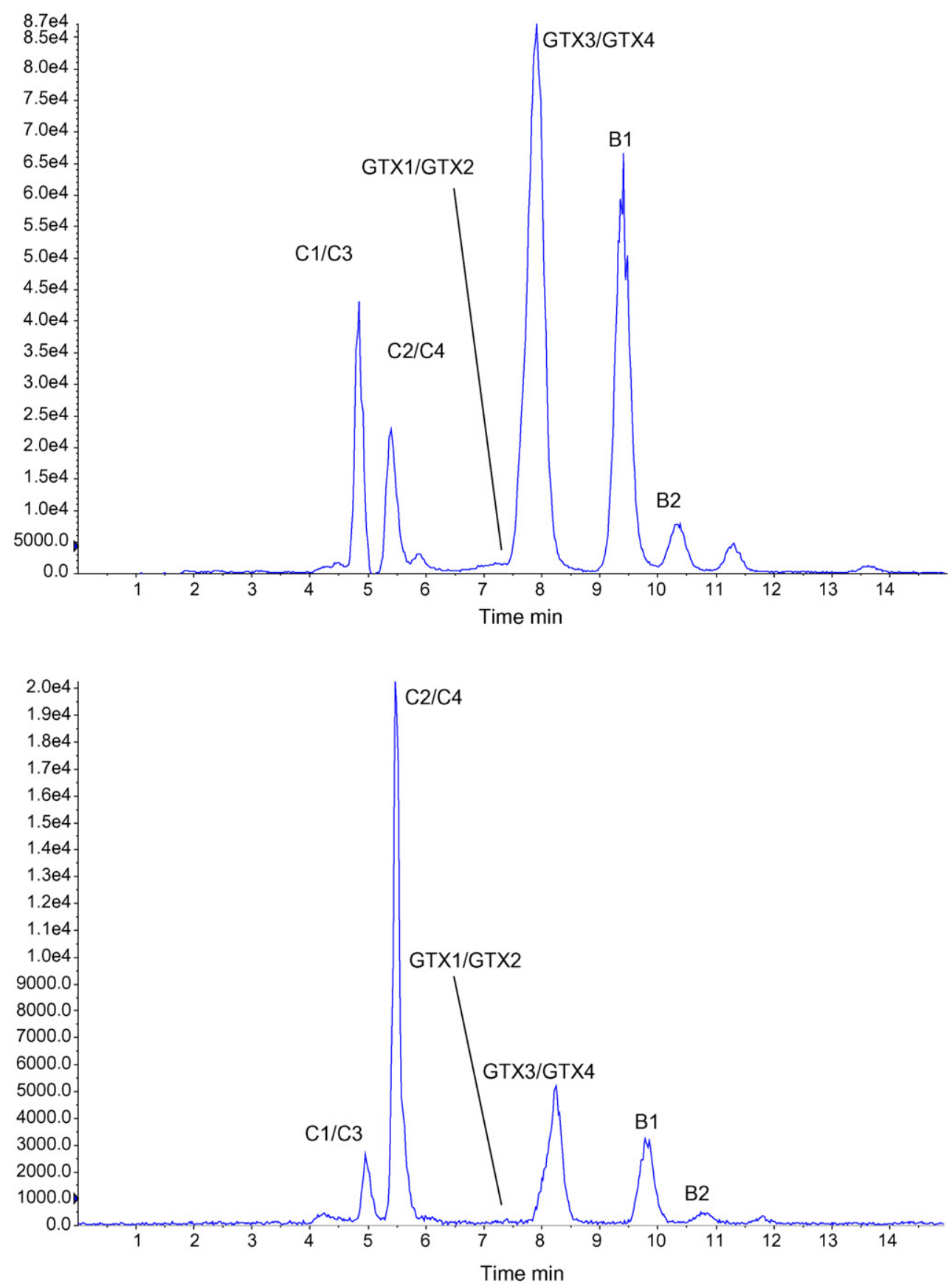

Fig. 4. Total ion chromatogram of the PSP toxin extract from A. catenella; top: original concentration and bottom: 1:10 diluted.

upon that of the same sample diluted 1:10 with extraction buffer. Ionization of the C-toxins is clearly suppressed at higher sample concentrations. This makes it difficult to obtain an accurate quantitation of PSP toxins by HILIC-MS/MS if external calibration is used, and almost impossible if certified analytical standards for certain derivatives are lacking, which is the case for the C-toxins. Precise and accurate quantitation of the class of PSP toxins remains challenging and is best achieved by combining LC-FD and LC-MS/MS methods.

In marine dinoflagellates, the PSP toxin content (cell quota) may vary over time and is subject to changes in environmental conditions (Cembella, 1998). Yet at least 
among toxigenic members of the genus Alexandrium, the toxin profile is genetically determined and remains roughly constant over time (Cembella and Destombe, 1995). With few exceptions, such as extreme nutrient deprivation that may cause a shift in the toxin profile in senescent batch cultures (Boczar et al., 1988), isolates in exponential growth phase tend to maintain their "molecular fingerprint" of toxins in culture. This makes it possible to compare toxin profiles from Alexandrium species and strains in long-term cultures, even if the isolates were not collected at the same time. The profile of the Chilean A. catenella differs substantially from that of natural blooms and cultured isolates of the related species A. tamarense associated with shellfish toxicity and elevated fish mortalities in Nova Scotia, eastern Canada (Cembella et al., 2002). The toxin composition of the A. catenella from Chile, with a high relative contribution of the $N$-sulfocarbamoyl toxins, especially $\mathrm{C} 1 / \mathrm{C} 2$ and $\mathrm{B} 1$, is consistent with the results of previous analyses of this species from the temperate waters of the North East Pacific (Cembella et al., 1987), Chile (Carreto et al., 2001) and Korean waters (Kim et al., 2005). The presence of toxin B2 and a high proportion of GTX1 and GTX4 are also characteristic of both the Chilean isolate and of $A$. catenella from Washington State, USA, but these toxins are inconsistently represented in the profile of isolates from British Columbia (Cembella et al., 1987). The low percentage of the carbamoyl toxins NEO and STX is entirely consistent with the global pattern found for other A. catenella strains. The decarbamoyl toxins are rarely found in healthy actively growing dinoflagellates; they are more common in shellfish as metabolites of carbamoyl or $N$-sulfocarbamoyl precursors. The presence of dcGTX at trace levels in the Chilean strain may be correct, but it is likely that (if present) the decarbamoyl toxins were overlooked in previous analyses of this species when standards and confirmatory methods were lacking.

Several studies have demonstrated differences in the relative levels of the various PSP toxin components in toxic dinoflagellates and different shellfish species collected in the same area (Oshima et al., 1976; Onoue et al., 1981). After consideration of many caveats, including the likelihood of selective retention and elimination of particular toxin analogues, metabolic transformations, and facile conversions due to physicochemical factors (e.g., $\mathrm{pH}$, temperature), it is also possible to reasonably compare the toxin profiles of shellfish with those of the causative dinoflagellates (Oshima et al., 1990; Cembella et al., 1993). In Fig. 5 we compared the toxin profile of a Chilean strain of $A$.

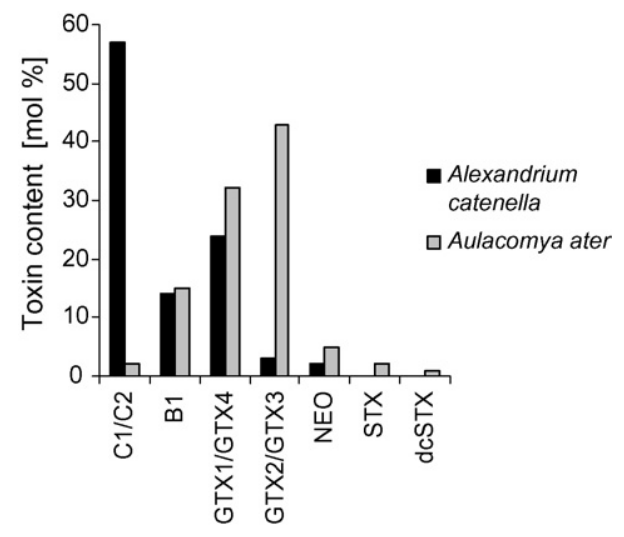

Fig. 5. PSP toxin profiles ( $\mathrm{mol} \%)$ of the dinoflagellate A. catenella and the bivalve species Aulacomya ater (replotted from Compagnon et al., 1998) from the Coastal Channel, XI Region, Chile.

catenella strain isolated from the Coastal Channel (XI Region) in 1994 to the toxin profile found in A. ater in the same region in 1996 (Compagnon et al., 1998). At first glance, the toxin profiles of the dinoflagellate and the shellfish do not seem to be a close match. Specifically, in contrast to the A. catenella profile, in $A$. ater the toxins $\mathrm{C} 1 / \mathrm{C} 2$ are present in only very low relative amounts, whereas NEO and STX are enhanced. Furthermore the ratios of the epimeric pairs GTX4/ GTX1 and GTX3/GTX2 are reversed. Nevertheless these differences can be largely accounted for via metabolic conversions and differences in the methodology of sample preparation. In vitro studies comparing bioconversions of purified PSP toxins in tissue homogenates of shellfish of different clam species (Fast et al., 2006) and differences in toxin profiles in field specimens of various bivalves, including sea scallops (Placopecten magellanicus) and surf clams ("quahogs") (Cembella et al., 1993) from the same geographical areas have demonstrated differential capacity for toxin biotransformation. Thus, conversion of $N$-sulfocarbamoyl toxins (e.g., $\mathrm{C} 1 / \mathrm{C} 2, \mathrm{~B} 1 / \mathrm{B} 2$ ) to the corresponding carbamoyl analogues (GTX2/GTX3, STX/NEO) in shellfish tissues can occur due the activity of natural reductants such as glutathione or to activity of enzymes such as sulfotransferases.

Simple enantiomeric toxin conversions via keto-enol tautomery (epimerization) of the $\beta$-epimers (e.g., $\mathrm{C} 2$, GTX3, GTX4) produced by the dinoflagellate to their $\alpha$ analogues (e.g., C1, GTX2, GTX1) in shellfish occurs spontaneously in response to physico-chemical factors, such as $\mathrm{pH}$. The ratio of the enantiomeric pairs GTX1/ GTX4 and GTX2/GTX3 determined in A. ater was 3:1, which is the thermodynamic equilibrium. However, in A. catenella the energetically less stable enantiomers 
GTX4 and GTX3 were more abundant than their respective partners. This is strong evidence that $A$. catenella produces only one enantiomer (the $\beta$-form), and it is very likely that epimerization takes place after biosynthesis. At this point it is not clear whether epimerization occurs within intact live cells or if it is exclusively a sample preparation effect. This is also the reason why amounts of enantiomeric pairs should only be given as sums, unless it has been proven that the respective experimental conditions do not alter the ratios. Here we provide the amounts of the single enantiomers only for comparison, but we do not claim that they represent a stable accuracy.

Sample preparation is another factor that may account for the difference in toxin profile between the shellfish and the dinoflagellate putatively responsible for the toxicity. We extracted A. catenella cells with $0.03 \mathrm{M}$ acetic acid at room temperature, whereas the A. ater samples were processed according to the standard mouse bioassay protocol (AOAC, 1990), which includes boiling the samples in $0.1 \mathrm{M}$ hydrochloric acid. Heating with hydrochloric acid is also used to convert $N$-sulfocarbamoyl toxins into the corresponding carbamoyl toxins for the indirect determination of $\mathrm{N}$-sulfocarbamoyl toxins, for which standards are not available.

Desulfonation by enzymatic activity or natural reductants (e.g. glutathione) in shellfish and acidic hydrolysis during sample preparation act in the same direction, namely the conversion of C-toxins into gonyautoxins. The chemical instability of the $\mathrm{N}$ sulfocarbamoyl C-toxins is also reflected in their mass spectra. The $\mathrm{N}-\mathrm{S}$ bond is the weakest in the molecule, and desulfonation of the C-toxins already occurs in the ion-source of the mass spectrometer. Due to the insource fragmentation and desulfonation of the C-toxins, their mass spectra are almost identical to those of their respective desulfonated gonyautoxins (compare spectra of C2 and GTX3, and C4 and GTX4 in Fig. 3). In the mass spectra of C-toxins, pseudo-molecular ions are never observed, but their respective $\left[M+\mathrm{H}-\mathrm{SO}_{3}\right]$ fragments are detectable.

Taking into account the chemical lability of the Ctoxins, it is obvious that the high percentages of GTX2 and GTX3 in A. ater do not reflect the original toxin composition of the causative organism, but are rather a result of shellfish metabolic activity and sample treatment artefacts. Interpreted with knowledge of the cited metabolic and physico-chemical transformations, the reconstructed profile from the shellfish fits very well with the scenario of contamination by $A$. catenella. Interestingly $\mathrm{C}_{11}$-sulfated $\mathrm{C}$-toxins are almost quantita- tively desulfonated, whereas $\mathrm{C}_{11}$-unsulfated $\mathrm{B} 1$ remains unaffected and is found in comparable amounts in the producing dinoflagellates as well as in shellfish. If in addition to the $\mathrm{N}$-desulfonation, a desulfatation at $\mathrm{C}_{11}$ takes place, $\mathrm{C} 1$ and $\mathrm{C} 2$ will be finally converted to $\mathrm{STX}$ (Laycock et al., 1995), which makes up 2\% of the total toxin in A. ater but is found only in trace amounts in $A$. catenella.

A few species of shellfish, particularly clams such as Spisula solidissima and Protothaca staminea, are known to metabolize PSP toxins by cleaving the carbamoyl group and thus forming decarbamoyl toxins (Sullivan et al., 1983; Cembella and Shumway, 1993; Cembella et al., 1994; Fast et al., 2006). Decarbamoyl toxins are rarely found in dinoflagellates, but there some exceptions - certain strains of Gymnodinium catenatum produce dcGTX2 and dcGTX3, and dcSTX sometimes occurs in small quantities in the tropical species Pyrodinium bahamense var. compressum (cited in Cembella, 1998).

The decarbamoyl toxins are almost completely absent from Alexandrium, and the trace levels occasionally reported must be regarded cautiously since the carbamoylase enzyme has never been reported from the dinoflagellates. The presence of substantial decarbamoyl toxins in shellfish is typically the result of post-digestive enzymatic conversion by endogenous carbamoylase produced by shellfish. This metabolic activity seems to be relatively low in A. ater, because dcSTX makes up only $1 \%$ of total PSP toxin content. Decarbamoyl gonyautoxins were not measured by (Compagnon et al., 1998), probably due to technical limitations and/or the absence of reference standards, but it is unlikely that they were substantially present because the carbamoylase enzyme that converts STX to dcSTX is also active (but with different affinity) in converting GTX2/GTX3 and their precursors C1/C2 to their respective decarbamoyl analogues.

\section{Conclusion}

The toxin profile obtained for a Chilean strain of $A$. catenella is generally characteristic of that found in populations of this species from the Pacific Ocean in the northern hemisphere. When corrected for predictable metabolic conversions in shellfish and expected sample preparation artefacts, it is also consistent with that reported for the suspension-feeding mytilid A. ater collected later from this same region of the Chilean coast. Specifically, the high relative concentration of GTX2 found in the shellfish is best explained via conversion of the predominant toxin $\mathrm{C} 2$ toxin in $A$. 
catenella via desulfonation and epimerization. The same interpretation applies to the ratios of GTX1 and GTX4 found in A. ater and A. catenella, respectively, whereby the dinoflagellate presents a higher mole percentage of the thermodynamically less stable enantiomer GTX4 than the shellfish. The strong circumstantial link between the presence of $A$. catenella blooms and corresponding shellfish toxicity and toxin profile in the Chilean blue mussel M. chilensis (Lagos, 2003) led to the conclusion that this dinoflagellate is a major source organism for PSP toxins in Chile. The complete analysis of toxin profiles supported by LCMS provided here is further evidence that in the south central region of Chile, A. catenella is the predominant (if not exclusive) source of PSP toxin contamination in shellfish. When cautiously interpreted, such analyses of toxin profiles, particularly involving confirmatory methods such as LC-MS, can provide new insights into patterns and sources of toxin accumulation in marine food webs.

\section{Acknowledgements}

The authors thank Dr. Sandra Madariaga and Ms. Miriam Seguel, Universidad Austral de Chile, Puerto Montt for the supply of cultured A. catenella cells from Southern Chile and Ms. Annegret Müller, AWI, Bremerhaven for LC-FD analysis and hydrolysis of the samples.[SES]

\section{References}

Andrinolo, D., Iglesias, V., García, C., Lagos, N., 2002. Toxicokinetics and toxicodynamics of gonyautoxins after an oral toxin dose in cats. Toxicon 40, 699-709.

AOAC, 1990. Paralytic shellfish poison. Biological method. Final action. In: Hellrich, K. (Ed.), Official Methods of Analysis. Association of Official Analytical Chemists. Arlington, VA, USA, pp. 881-882.

Baker, T.R., Doucette, G.J., Powell, C.L., Boyer, G.L., Plumley, F.G., 2003. GTX4 imposters: characterization of fluorescent compounds synthesized by Pseudomonas stutzeri SF/PS and Pseudomonas/Alteromonas PTB-1, symbionts of saxitoxin-producing Alexandrium spp. Toxicon 41, 339-347.

Biré, R., Krys, S., Frémy, J.-M., Dragacci, S., 2003. Improved solidphase extraction procedure in the analysis of paralytic shellfish poisoning toxins by liquid chromatography with fluorescence detection. J. Agric. Food Chem. 51, 6386-6390.

Boczar, B.A., Beitler, M.K., Liston, J., Sullivan, J.J., Cattolico, R.A., 1988. Paralytic shellfish toxins in Protogonyaulax tamarensis and Protogonyaulax catenella in axenic culture. Plant Physiol. 88, 1285-1290.

Carmichael, W.W., 1994. The toxins of cyanobacteria. Sci. Am. 270, $78-86$.

Carreto, J.I., Carignan, M.O., Montoya, N.G., 2001. Comparative studies on mycosporine-like amino acids, paralytic shellfish toxins and pigment profiles of the toxic dinoflagellates Alexandrium tamarense, A. catenella and A. minutum. Mar. Ecol. Prog. Ser. 223, 49-60.

Cassis, D., Muñoz, P., Avaria, S., 2002. Temporal change of the phytoplankton between 1993 and 1998 in a fixed station inside Aysén fjord, Chile $\left(45^{\circ} 26^{\prime} \mathrm{S} 73^{\circ} 00^{\prime} \mathrm{W}\right)$. Rev. Biol. Mar. Oceanograf. 37, 43-65.

Cembella, A.D., 1998. Ecophysiology and metabolism of paralytic shellfish toxins in marine microalgae. In: Anderson, D.M., Cembella, A.D., Hallegraeff, G.M. (Eds.), Physiological Ecology of Harmful Algal Blooms. Springer Verlag, Heidelberg, pp. 381-403.

Cembella, A.D., Shumway, S.E., 1993. Anatomical and spatio-temporal variation in PSP toxin composition in natural populations of the surfclam Spisula solidissima in the Gulf of Maine. In: Lassus, P., Arzul, G., Erard-Le Denn, E., Gentien, P., Marcaillou-Le Baut, C. (Eds.), Proceedings of the Sixth International Conference on Toxic Marine Phytoplankton. Lavoisier, Nantes, France, pp. 421426.

Cembella, A.D., Destombe, C., 1995. Genetic differentiation among Alexandrium populations from eastern Canada. In: Proceedings of the Seventh International Conference on Marine Toxic Phytoplankton, IOC(UNESCO), Sendai, Japan, pp. 447450.

Cembella, A.D., Shumway, S.E., Lewis, N.I., 1993. Anatomical distribution and spatio-temporal variation in paralytic shellfish toxin composition in two bivalve species from the Gulf of Maine. J. Shellfish Res. 12, 389-403.

Cembella, A.D., Shumway, S.E., Larocque, R., 1994. Sequestering and putative biotransformation of paralytic shellfish toxins by the sea scallop Placopecten magellanicus: seasonal and spatial scales in natural populations. J. Exp. Mar. Biol. Ecol. 180, 1-22.

Cembella, A.D., Sullivan, J.J., Boyer, G.L., Taylor, F.J.R., Andersen, R.J., 1987. Variation in paralytic shellfish toxin composition within the Protogonyaulax tamarensis/catenella species complex; red tide dinoflagellates. Biochem. Syst. Ecol. 15, 171-186.

Cembella, A.D., Quilliam, M.A., Lewis, N.I., Bauder, A.G., Dell'Aversano, C., Thomas, K., Jellett, J., Cusack, R.R., 2002. The toxigenic marine dinoflagellate Alexandrium tamarense as the probable cause of mortality of caged salmon in Nova Scotia. Harmful Algae 1, 313-325.

Compagnon, D., Lembeye, G., Marcos, N., Ruiz-Tagle, N., Lagos, N., 1998. Accumulation of paralytic shellfish poisoning toxins in the bivalve Aulacomya ater and two carnivorous gastropods Concholepas concholepas and Argobuccinum ranelliformes during an Alexandrium catenella bloom in southern Chile. J. Shellfish Res. 17, 67-73.

Dell'Aversano, C., Hess, P., Quilliam, M.A., 2005. Hydrophilic interaction liquid chromatography-mass spectrometry for the analysis of paralytic shellfish poisoning (PSP) toxins. J. Chromatogr. A 1081, 190-201.

Fast, M.D., Cembella, A.D., Ross, N.W., 2006. In vitro transformation of paralytic shellfish toxins in the clams Mya arenaria and Protothaca staminea. Harmful Algae 5, 79-90.

García, C., Mardones, P., Lagos, N., Sfeir, A., 2004. Simultaneous presence of paralytic and diarrheic shellfish poisoning toxins in Mytilus chilensis samples collected in the Chiloe Island, Austral Chilean fjords. Biol. Res. 37, 721-731.

García, C., Lagos, M., Truan, D., Lattes, K., Véjar, O., Chamorro, B., Iglesias, V., Andrinolo, D., Lagos, N., 2005. Human intoxication with paralytic shellfish toxins: clinical parameters and toxin analysis in plasma and urine. Biol. Res. 38, 197-205. 
Guillard, R.R.L., 1972. Culture of phytoplankton for feeding marine invertebrates. In: Smith, W.L., Chanley, M.H. (Eds.), Culture of Marine Invertebrate Animals. Plenum Press, New York, pp. 29-60.

Guzmán, L., Pacheco, H., Pizarro, G., Alarcón, C., 2002. Alexandrium catenella y veneno paralizante de los mariscos en Chile. In: Sar, E.A., Ferrario, M.E., Reguera, B. (Eds.), Floraciones Algales Nocivas en el Cono Sur Americano. Instituto Español de Oceanographía, Madrid, pp. 235-256.

Hall, S., Strichartz, G., Moczydlowski, E., Ravindran, A., Reichardt, P.B., 1990. The saxitoxins. Sources, chemistry, and pharmacology. In: Hall, S., Strichartz, G. (Eds.), Marine Toxins: Sources, Chemistry and Pharmacology. American Chemical Society, Washington, DC, pp. 29-65.

Jaime, E., Hummert, C., Hess, P., Luckas, B., 2001. Determination of paralytic shellfish poisoning toxins by high-performance ionexchange chromatography. J. Chromatogr. A 929, 43-49.

Kao, C.Y., Walker, S.E., 1982. Active groups of saxitoxin and tetrodotoxin as deduced from actions of saxitoxin analogues on frog muscle and squid axon. J. Physiol. 323, 619.

Kim, C.-J., Kim, C.-H., Sako, Y., 2005. Paralytic shellfish poisoning toxin analysis of the genus Alexandrium (Dinophyceae) occurring in Korean coastal waters. Fish. Sci. 71, 1-11.

Kodama, M., 2000. Paralytic shellfish poisoning: ecology, classification, and origin. In: Botana, L.M. (Ed.), Seafood and Freshwater Toxins; Pharmacology, Physiology and Detection. Marcel Dekker, New York, pp. 125-149.

Lagos, N., 2003. Paralytic shellfish poisoning phycotoxins: occurrence in South America. Comments Toxicol. 9, 175-193.
Laycock, M.V., Kralovec, J., Richards, R., 1995. Some in vitro chemical interconversions of paralytic shellfish poisoning (PSP) toxins useful in the preparation of analytical standards. J. Mar. Biol. 3, 121-125.

Mortensen, A.M., 1985. Massive fish mortalities in the Faroe Islands caused by a Gonyaulax excavata red tide. In: Anderson, D.M., White, A.W., Baden, D.G. (Eds.), Proceedings of the Third International Conference on Toxic Dinoflagellates, St. Andrews, pp. $165-170$.

Muñoz, P., 1985. Revisión taxonómica de los dinoflagelados de Chile. Rev. Biol. Mar. Oceanograf. 21, 31-60.

Onodera, H., Satake, M., Oshima, Y., Yasumoto, T., Carmichael, W.W., 1997. New saxitoxin analogues from the freshwater filamentous cyanobacterium Lyngbya wollei. Nat. Toxins 5, 146-151.

Onoue, Y., Noguchi, T., Maruyama, J., Hashimoto, K., Ikeda, T., 1981. New toxins separated from oysters and Protogonyaulax catenella from Senzaki Bay, Yamaguchi Prefecture. Bull. Jpn. Soc. Sci. Fish. 47, 1643.

Oshima, Y., Fallon, W.E., Shimizu, Y., Noguchi, T., Hashimoto, Y., 1976. Toxins of the Gonyaulax sp. and infested bivalves in Owase Bay. Bull. Jpn. Soc. Sci. Fish. 42, 851-856.

Oshima, Y., Sugino, K., Itakura, H., Hirota, M., Yasumoto, T., 1990. Comparative studies on paralytic shellfish toxin profile of dinoflagellates and bivalves. In: Granéli, E., Sundström, B., Edler, L., Anderson, D.M. (Eds.), Toxic Marine Phytoplankton. Elsevier, New York, pp. 391-396.

Sullivan, J.J., Iwaoka, W.T., Liston, J., 1983. Enzymatic transformation of PSP toxins in the littleneck clam (Protothaca staminea). Biochem. Biophys. Res. Commun. 114, 465-472. 